\title{
AUTOMAÇÃO RESIDENCIAL DE BAIXO CUSTO COM CONTROLE POR RÁDIO FREQUÊNCIA
}

\author{
André Luís da Silva Pinheiro \\ Doutor em Engenharia Nuclear pela Universidade Federal do Rio de Janeiro (UFRJ) \\ Rio de Janeiro, RJ, Brasil \\ apinheiro99@gmail.com \\ Antônio José Dias da Silva \\ Mestre em Sistemas de Informação pela Universidade Federal do Rio de Janeiro (UFRJ) \\ Professor do Centro Universitário Augusto Motta - UNISUAM \\ Rio de Janeiro, RJ, Brasil \\ antoniojoseds@gmail.com \\ Geraldo Motta Azevedo Júnior \\ Doutor em Engenharia Elétrica pela Universidade Federal do Rio de Janeiro (COPPE/UFRJ) \\ Professor do Centro Universitário Augusto Motta - UNISUAM \\ Rio de Janeiro, RJ, Brasil \\ geraldomotta@unisuam.edu.br \\ Tiago Coelho Premerl Leite \\ Graduando de Engenharia Elétrica da UNISUAM, Rio de Janeiro, RJ, Brasil \\ tiagopremerl@gmail.com
}

\begin{abstract}
RESUMO
Sistemas de automação residencial que se utilizam de tecnologias modernas, normalmente possuem um valor de mercado elevado. Tais sistemas, agregam também uma alta complexidade de implementação, sem levar em conta que muitas das vezes, necessita de alguma arquitetura previamente existente (por exemplo uma rede $\mathrm{Wi}-\mathrm{Fi}$ ). Sendo assim, praticamente tais sistemas ficam restritos ao público consumidor de maior poder aquisitivo. $O$ principal objetivo deste projeto, consiste em reduzir os encargos de produção e como consequência o custo dos sistemas de automação residencial, para que pessoas de baixa renda, possam usufruir de tal tecnologia. A utilização de transmissores e receptores de rádio frequência para o acionamento de comandos ao invés de tecnologias modernas de transmissão, como redes Wi-Fi, traz a redução dos encargos de produção e maior facilidade de implantação pois, não existe a necessidade de associar sistemas de tecnologia mais complexas ao sistema de automação. Para realizar a comunicação entre os dispositivos a serem automatizados serão utilizados componentes como o HT12E e HT12D (Encoder e Decoder para RF) juntamente com as chaves de acionamento e luzes sinalizadoras no controle remoto para execução de comandos em qualquer lugar da casa. Os resultados obtidos atenderam a proposta do projeto. O custo final ficou em $\mathrm{R} \$ 102,10$. Neste valor, está incluso a construção do controle e do atuador, o que possibilitou maior acessibilidade ao sistema pelas classes menos favorecidas. Sendo assim, pode-se dizer que o objetivo do projeto foi alcançado validando o trabalho realizado.
\end{abstract}

Palavras-chave: Automação, residencial, baixo custo, acessibilidade, radio frequência 


\title{
LOW-COST RESIDENTIAL AUTOMATION WITH RADIO FREQUENCY CONTROL
}

\begin{abstract}
Home automation systems that use modern technologies usually have a high market value. Such systems also add a high complexity of implementation, without considering that they often need some previously existing architecture (for example, a Wi-Fi network). Therefore, practically such systems are restricted to consumers with greater purchasing power. The main objective of this project is to reduce production costs and, therefore, the cost of home automation systems so that low-income people can take advantage of this technology. The use of radiofrequency transmitters and receivers to trigger commands instead of modern transmission technologies, such as Wi- $\mathrm{Fi}$ networks, brings a reduction in production charges and greater ease of deployment, as there is no need to associate systems with more complex technology to the automation system. To carry out the communication between the devices to be automated, components such as the HT12E and HT12D (Encoder and Decoder for RF) will be used along with the activation keys and signaling lights on the remote control to execute commands anywhere in the house. The results obtained met the project proposal. The final cost was $\mathrm{R} \$ 102,10$. In this value, the construction of the control and the actuator is included, which allowed greater access to the system by the less favored classes. Thus, it can be said that the project objective was achieved by validating the work performed.
\end{abstract}

Keywords: Automation, residential, low cost, accessibility, Radio frequency

\section{INTRODUÇÃO}

\subsection{Metodologia}

A primeira etapa para o desenvolvimento do projeto será realizar o levantamento de custo para implantação de projetos modernos de automação residencial de forma que ao final do projeto, seja possível realizar a comparação de valores para se confirmar a proposta deste trabalho, que é reduzir os encargos de produção e como consequência o custo dos sistemas de automação residencial, para que desta forma, pessoas de baixa renda possam usufruir de tal tecnologia. Para que seja possível realizar essa etapa, será feito um trabalho de pesquisa para encontrar um valor médio para implantação de um sistema básico de automação residencial. Ao mesmo tempo, o sistema proposto será desenvolvido a fim de que possa ser feita a comparação entre custos.

Já na segunda etapa do desenvolvimento do projeto, um protótipo será feito utilizando conhecimentos prévios na área de engenharia. Instrumentos de medição utilizados em eletrônica, tais como o multímetro utilizado para medição de tensões e correntes e um medidor de frequências para ajuste da frequência de transmissão e recepção. Para realizar a comunicação entre os dispositivos a serem automatizados serão utilizados componentes como o HT12E e HT12D (Encoder e Decoder para RF) juntamente com as chaves de acionamento e luzes sinalizadoras no controle remoto para execução de comandos em qualquer lugar da casa.

\begin{tabular}{l|l|l|l|l|l|r} 
Projectus & Rio de Janeiro & V.5 & N.1 & P. $54-74$ & 2020
\end{tabular}




\subsection{Revisão Bibliográfica}

\subsubsection{Automação Residencial na Atualidade}

Atualmente é possível encontrar a cada dia que passa dispositivos eletrônicos que apresentam de algum modo uma forma de comunicação que os integra a uma interface com o usuário final. Isso ocorreu mais frequentemente após a chegada e popularização de smartphones onde agora é possível notar um avanço no crescimento que está mais acelerado com relação às tecnologias de automação e controle para acessórios utilizados no cotidiano. Foi natural o processo que tornou os smartphones uma interface comum para o controle de dispositivos na automação residencial. Isso se deve ao fato desses aparelhos estarem continuamente junto ao ser humano em suas atividades diárias. Um estudo realizado pela associação brasileira de automação residencial e predial (MURATORI, 2017), estimou alguns números referentes à quantidade de residências que possuem tais sistemas em alguns países ao redor do mundo (Figura 1).

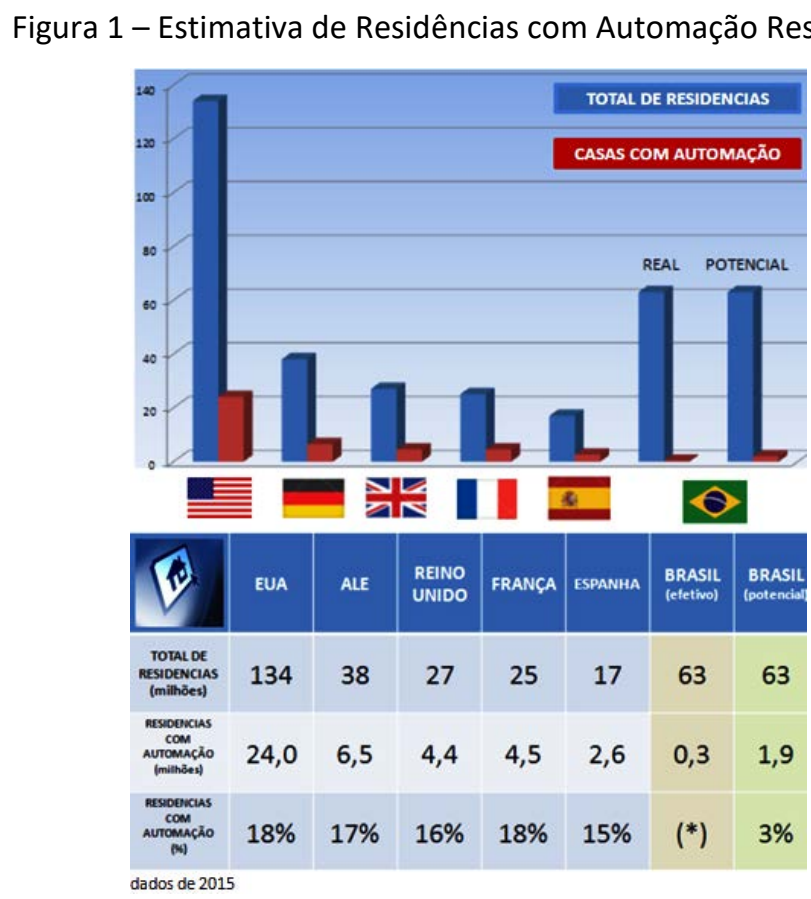

Fonte: Adaptado de http://jundiagora.com.br/casa-igual/, acessado em 25/11/2018.

Os aparelhos celulares que apresentam maior liberdade para se trabalhar com automação residencial são os que possuem a plataforma Android, uma vez que esse sistema operacional possui código aberto e assim, possibilita que muitos aplicativos sejam criados, além da sua central de downloads já possuir muitos destes aplicativos que possibilitam os aparelhos celulares serem usados como controles para tais sistemas de automação. A grande vantagem do código aberto está na possibilidade dos desenvolvedores, tanto amadores quanto profissionais, terem a chance e flexibilidade para tentarem novas aplicações. "O Código Aberto é um termo que se refere a um 
software cujo código está disponível para download por qualquer pessoa e a uma filosofia de criação de aplicativos voltada para a colaboração entre desenvolvedores." (KURTZ, 2016).

A automação residencial de dispositivos discretos (Figura 2) é o tipo de sistema mais observado atualmente. O principal destaque desse modelo é a forma de comunicação que liga a IHM até um dispositivo que será automatizado, conferindo-Ihe novos recursos como, por exemplo, a opção de acioná-lo remotamente, temporizá-lo, agendar o seu ligamento ou desligamento, definir a forma como este deve operar, entre outras possibilidades.

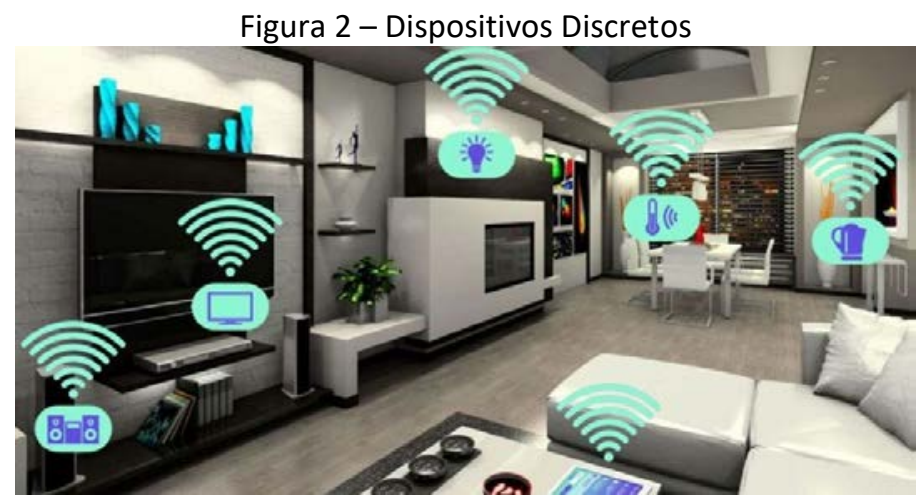

Fonte: Adaptado de http://blog.agmar.com.br/automacao-residencial-o-futuro-nas-suas-maos/, acessado em $19 / 11 / 2018$

\subsubsection{Arduino Mega e Ethernet Shield}

“O Arduino é uma plataforma formada por dois componentes: A placa, que é o Hardware e a IDE Arduino, que é o Software onde se escreve o que se quer que a placa faça". (MOTA, 2017). A grande vantagem desta interface (Figura 3) é que ela possui uma grande facilidade de utilização, o que faz com que muitos usuários, mesmo sendo iniciantes nas áreas de eletrônica e robótica, sejam capazes de manuseá-los e aplicá-los em projetos diversos. "Baseada no microcontrolador ATmega2560, possui 54 pinos de entradas e saídas digitais onde 15 destes podem ser utilizados como saídas PWM. Possui 16 entradas analógicas, 4 portas de comunicação serial” (SOUZA, 2014). Esta placa é comumente aplicada em projetos que necessitem de muitos pinos para entrada e saída de informações além do fato da sua memória para programação ser maior em comparação a outras placas Arduino. 
Figura 3 - Placa Arduino Mega

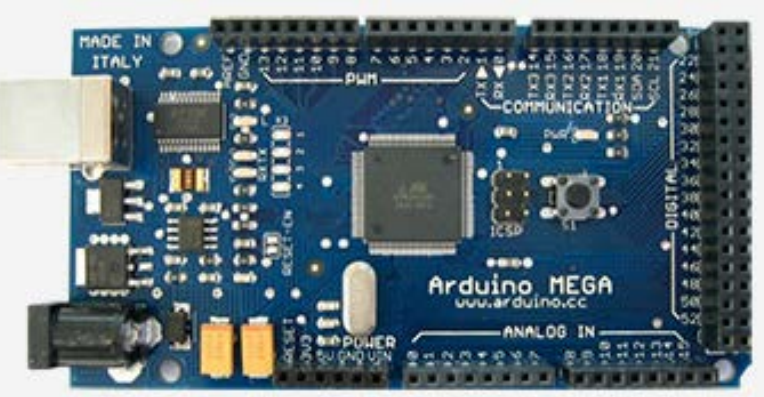

Fonte: Adaptado de https://www.arduino.cc/en/Main/arduinoBoardMega/, acessado em 25/11/2018.

O Ethernet Shield (Figura 4) é um componente da família Arduino que possui o objetivo de conectar o sistema à rede ethernet, possibilitando ao usuário ter acesso às informações através da sua rede local, mas também permite controlar dispositivos ligados a ele de qualquer lugar onde esteja utilizando a internet. "O Ethernet Shield, possui o chip Wiznet W5100 e suporta até quatro conexões de socket simultaneamente. O shield possui um slot para cartão de memória (micro SD), onde é possível armazenar arquivos que podem ser enviados pela rede local / internet, e possui também bibliotecas para serem utilizadas pelo Arduino." (OLIVEIRA, 2018).

Figura 4 - Placa Ethernet Shield

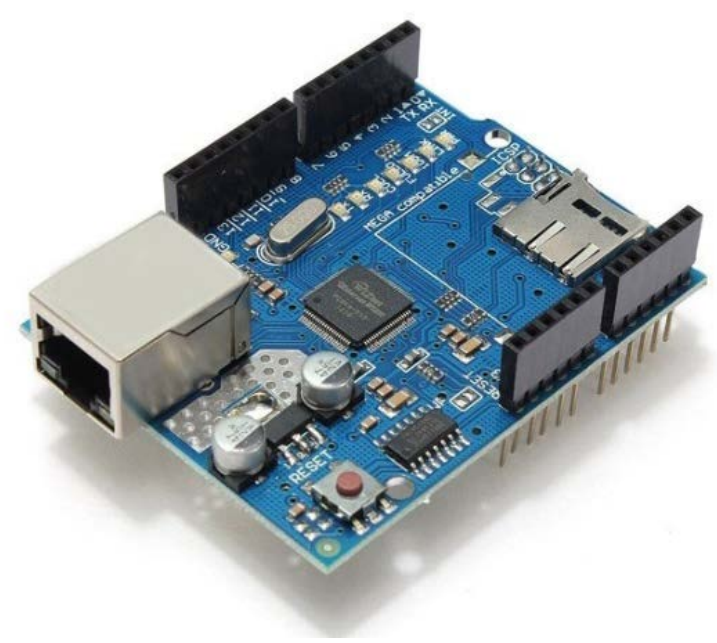

Fonte: Adaptado de http://www.baudaeletronica.com.br/ethernet-shield-w5100-para-arduino.html, acessado em $25 / 11 / 2018$

\subsubsection{Automação residencial com rádio frequência}

Os sistemas de automação residencial que operam utilizando rádio frequência são uma solução simples e eficiente para a questão do custo envolvido na construção e implantação. Seu desenvolvimento é baseado principalmente no componente HT12E e seu par, HT12D (Figura 5). Os dois componentes atuam em conjunto, codificando e decodificando sinais de RF que são gerados mediante o acionamento de comandos no controlador (que pode ser uma central ou um simples controle remoto, por exemplo). “O Cl HT12E gera um tom que somente o decodificador HT12D será 
capaz de decifrá-lo, a codificação é necessária para que um sistema de rádio controle não interfira em outro sistema de rádio controle, mesmo que funcione na mesma frequência." (IBYTES, 2016).

Figura 5 - Circuitos Integrados HT12E e HT12D
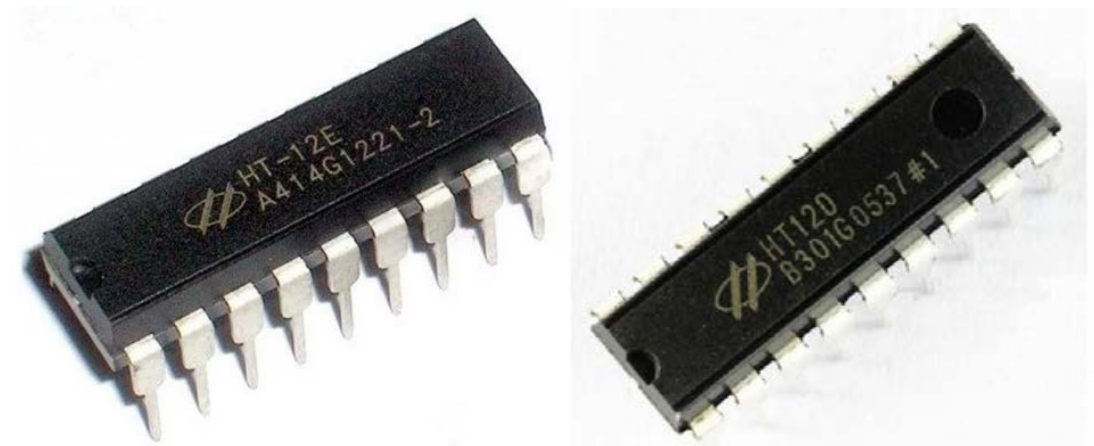

Fonte: Adaptado de http://www.baudaeletronica.com.br/circuito-integrado-ht12e.html e http://www.baudaeletronica.com.br/circuito-integrado-ht12d.html, acessado em 25/11/2018.

\section{DESENVOLVIMENTO}

\subsection{Custo de Dispositivos de Automação}

2.1.2. Custo da automação com dispositivos cabeados

Os valores da Tabela 1 foram obtidos através de pesquisa com o objetivo de especificar valores dos sistemas que utilizam o padrão X10 (X10 HOME AUTOMATION, 2018) de comunicação.

Tabela 1 - Custo de dispositivos com padrão X10 de comunicação

\begin{tabular}{|c|c|}
\hline Produto & Custo (R\$) \\
\hline Receptor para lluminação & 68,89 \\
\hline Controle Remoto de lluminação & 57,40 \\
\hline Atuador para lluminação & 68,89 \\
\hline Total & 195,18 \\
\hline Fonte: Os autores \\
\hline
\end{tabular}

2.1.2. Custo da automação com dispositivos sem fio

Os valores da Tabela 2 correspondem ao custo baseado no sistema WINK citado anteriormente, que utiliza redes sem fio para comunicação entre equipamentos, de forma que o comando venha através de um único controle manual.

Tabela 2 - Custo de dispositivos sem fio para automação

\begin{tabular}{|c|c|}
\hline Produto & Custo (R\$) \\
\hline WINK HUB 2 & 379,30 \\
\hline Lâmpada Sylvania Smart & 114,86 \\
\hline Total & 494,16 \\
\hline
\end{tabular}




\subsubsection{Custo da automação com Arduino mega e Ethernet Shield}

O custo relacionado à construção do sistema proposto com Arduino Mega e Ethernet Shield está representado na Tabela 3 abaixo:

Tabela 3 - Custo da Automação com Arduino Mega e Ether
\begin{tabular}{|c|c|} 
Dispositivos & Valor Escolhido (R\$) \\
\hline Placas com 6 Relés & 55,00 \\
\hline Sensor de Presença & 20,00 \\
\hline Cabos de Alimentação & 75,00 \\
\hline Arduino Mega & 80,00 \\
\hline Ethernet Shield & 52,00 \\
\hline Cabo IR & 45,00 \\
\hline Total & 327,00 \\
\hline
\end{tabular}

Fonte: (LIMA, NOBRE e ALENCAR, 2015).

2.2. Conceitos gerais do funcionamento

A ideia inicial para a construção do protótipo é fornecer em primeiro lugar a possibilidade de controlar dispositivos de dentro de uma residência. Para fins de construção será considerada uma distância média de controle de 30 a 40 metros, supondo que este valor se adeque a maioria das residências a que o projeto se destina. Sendo assim, o princípio de funcionamento do sistema está na transmissão via radiofrequência de sinais utilizando para isso um controle remoto com comandos específicos de ligar e desligar. A aplicabilidade desses comandos se amplia para todos os equipamentos a que este projeto se destina, por exemplo: luzes (estas podem ser acesas em conjunto ou individualmente, dependendo de como a instalação elétrica inicial da residência foi realizada ou como o atuador será instalado), ventiladores, abajures, abertura de cortinas, trancas elétricas de portas e portões, portões automáticos, entre outros.

Para que isso seja possível, o projeto se iniciará com o desenvolvimento do controle, ou seja, a central de automatização estará ao alcance de qualquer pessoa dentro da residência, podendo ser facilmente transportada para qualquer lugar da casa, o que se propõe a ser uma alternativa simples para a questão da acessibilidade até para pessoas com restrições físicas.

Já os atuadores serão os dispositivos responsáveis por receber o sinal do controle remoto e atuar de acordo com a função que Ihe foi designada como foi exemplificado anteriormente. Os atuadores precisarão ter uma pequena diferença no relé de chaveamento em função da carga que ele terá que suportar. É importante ressaltar que os atuadores farão o chaveamento do aparelho em que estarão conectados, ou seja, em conjunto com o próprio interruptor do equipamento o 
usuário realizará o comando de ligá-lo ou desligá-lo. Para que fique mais bem entendido: o sistema fornecerá a possibilidade de acionar aparelhos através do controle remoto sem eliminar a chance de fazê-lo pelo interruptor tradicional da instalação. É necessário que seja feito dessa forma para que em caso de qualquer problema com o controle ou atuador, ainda seja possível utilizar o aparelho.

Com relação à transmissão do sinal, o sistema contará com um transmissor e receptor RF numa frequência cuja codificação torne o sistema mais seguro e não permita que sinais que possam surgir na mesma frequência acionem ou interrompam o funcionamento de qualquer aparelho. Este sinal deverá utilizar a forma simplex de comunicação, ou seja, o transmissor e o receptor funcionarão apenas nas suas formas originais, não podendo inverter os papéis como em configurações semi-duplex ou duplex (SILVA, 2012). Além disso, trabalhará de forma omnidirecional, de forma a distribuir um sinal a vários destinatários, porém, apenas o receptor com a mesma codificação do transmissor conseguirá interpretar o sinal recebido.

\subsection{Detalhes do Funcionamento do Sistema de Controle}

O circuito eletrônico que compõe o controle remoto do sistema de automação residencial proposto começa pela sua alimentação individual composta por uma bateria de $9 \mathrm{~V}$, cuja tensão deve ser regulada para 5V, como visto na Figura 6 e na Figura 7, para atender às necessidades dos componentes do circuito através de um regulador de tensão de 5V, modelo LM7805. Vale ressaltar que os capacitores em questão possuem a função de estabilizadores de tensão. O capacitor C2 à esquerda do regulador procura estabilizar a tensão da fonte e o capacitor C1 da direita busca estabilizar a tensão de saída visto que a carga pode variar esta tensão em alguns milivolts.

Figura 6 - Circuito regulador de $5 \mathrm{~V}$ do controle

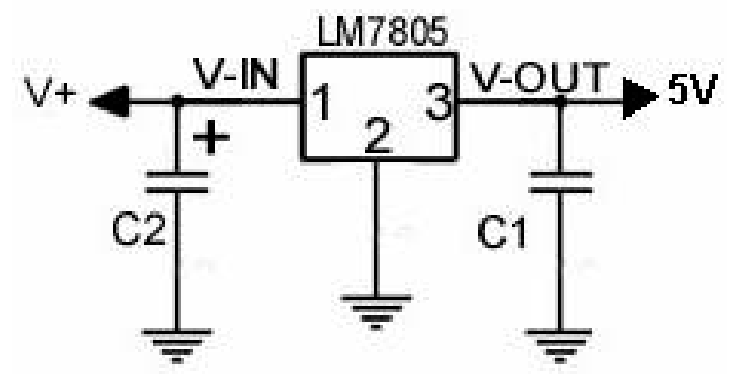

Fonte: Adaptado de http://baudaeletronica.blogspot.com/, acessado em 09/07/2019 


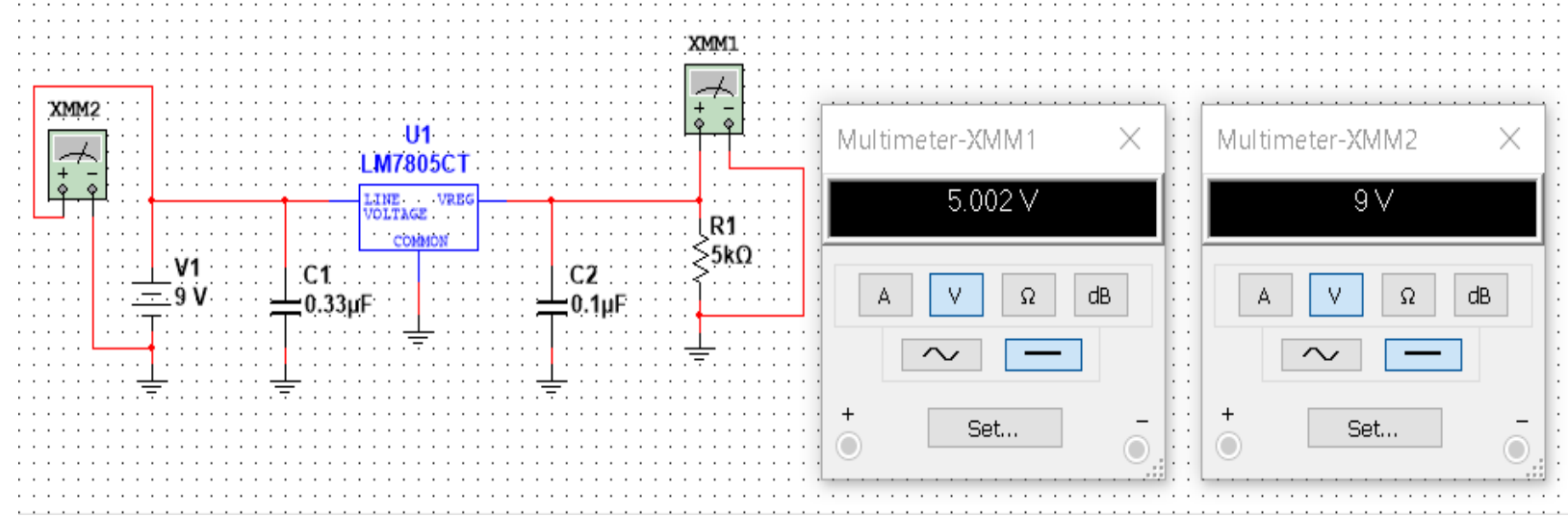

Fonte: Os autores

A Figura 8 mostra o protótipo da fonte do sistema de controle.

Figura 8 - Tensão regulada da fonte do sistema de controle

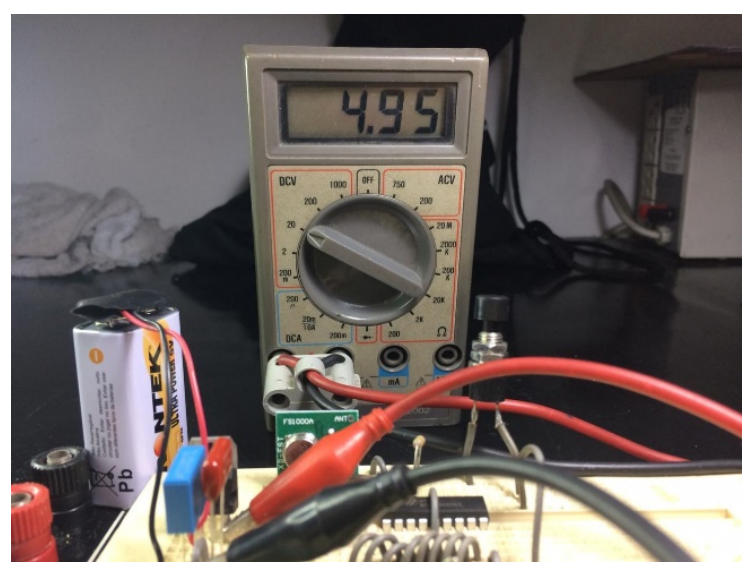

Fonte: Os autores

O bloco do circuito responsável pelo recebimento dos comandos é composto pelo componente HT12E, que é um circuito integrado cuja função é enviar um sinal de comando para um circuito transmissor pelo pino 17 (Data Out). Os botões que servirão para acionar os comandos são normalmente abertos e estarão localizados nos pinos 10 ao 13 do circuito integrado, sendo necessário apenas um pulso rápido para ligar e outro pulso no mesmo botão para desligar. Um resistor deve ser ligado entre os pinos 15 e 16 que determinará a frequência de oscilação. Os bits "um" e "zero" poderão ser reconhecidos através do sinal que será submetido a essa frequência. Ao ser enviado um sinal, o HT12E reconhecerá que deve enviar um bit "um" ou "zero" para o decodificador. O valor desse resistor deve seguir o gráfico da Figura 9. Através desse gráfico é possível escolher a frequência de oscilação do projeto e o seu respectivo resistor de oscilação observando também a tensão de alimentação do circuito. Para este projeto será utilizada a frequência de oscilação de $3 \mathrm{kHz}$ com uma tensão de alimentação de $5 \mathrm{~V}$, o que fornece um valor de resistor de $1 \mathrm{M} \Omega$. 
Figura 9 - Gráfico de frequência vs. tensão de alimentação do HT12E

Oscillator Frequency vs. Supply Voltage

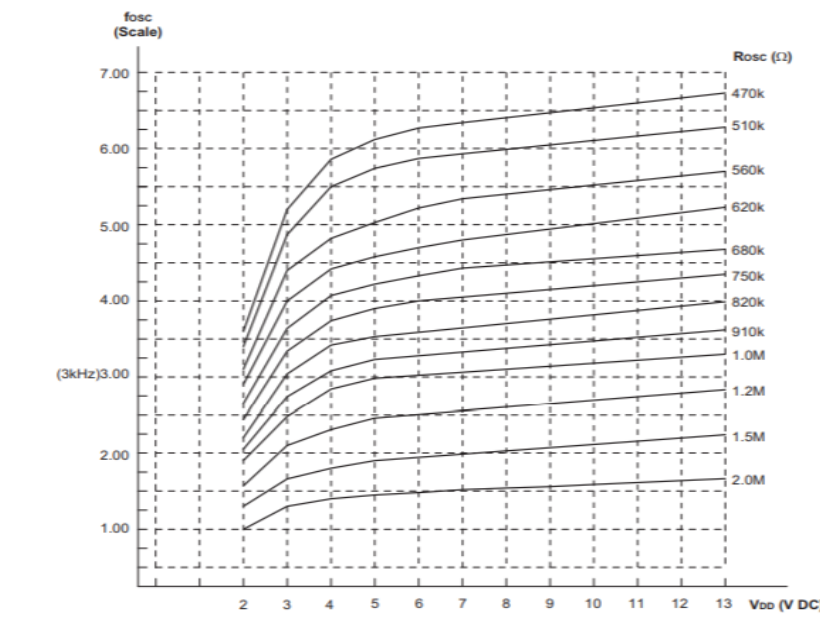

The recommended oscillator frequency is foSCD (decoder) $\cong 50$ fOSCE (HT12E encoder)

$\cong \frac{1}{3} f_{O S C E}(H T 12 A$ encoder $)$

Fonte: Adaptado de https://www.farnell.com/datasheets/1899539.pdf, acessado em 09/07/2019

Para realizar a transmissão do sinal, será utilizado um módulo transmissor RF 433Mhz. “O tipo de modulação da portadora de rádio frequência é o ASK - modulação por chaveamento de amplitude. Isto é, quando existe o bit 1 a portadora transmite o sinal de $433 \mathrm{MHz}$. Quando o bit é zero, nenhum sinal é transmitido." (MURTA, 2019). Sendo assim, toda vez que uma das chaves for pressionada, o transmissor receberá a informação e transmitirá com a codificação ajustada no $\mathrm{Cl}$ e na frequência pré-estabelecida. O pino intitulado "data" é onde a informação vinda do HT12E deve chegar. Os pinos Vcc e GND se referem à alimentação do transmissor. A tensão de operação do transmissor pode variar de 3,5 a $12 \mathrm{~V}$ e a alteração dessa tensão tem influência no alcance do sinal transmitido.

A codificação do sistema de controle está localizada nos pinos 1 ao 8 , que devem ser aterrados ou não conforme a escolha do projetista. Esta mesma codificação deve se repetir no seu par (HT12D) para que haja a interpretação correta do sinal. A codificação é importante porque impedirá que qualquer sinal vindo de outras fontes interfira no pleno funcionamento do sistema. Além da segurança, a codificação também permite que o controle consiga chavear mais de quatro atuadores apenas trocando a posição de um de seus terminais. Desta forma é possível controlar inúmeros atuadores apenas alterando a codificações destes e do controle. Para este projeto, será realizado o aterramento de todos os pinos de 1 a 8, tanto no HT12E como no HT12D, para que seja realizada a correta transmissão e interpretação do sinal. A Figura 10 mostra o circuito do controle do sistema de automação residencial. 


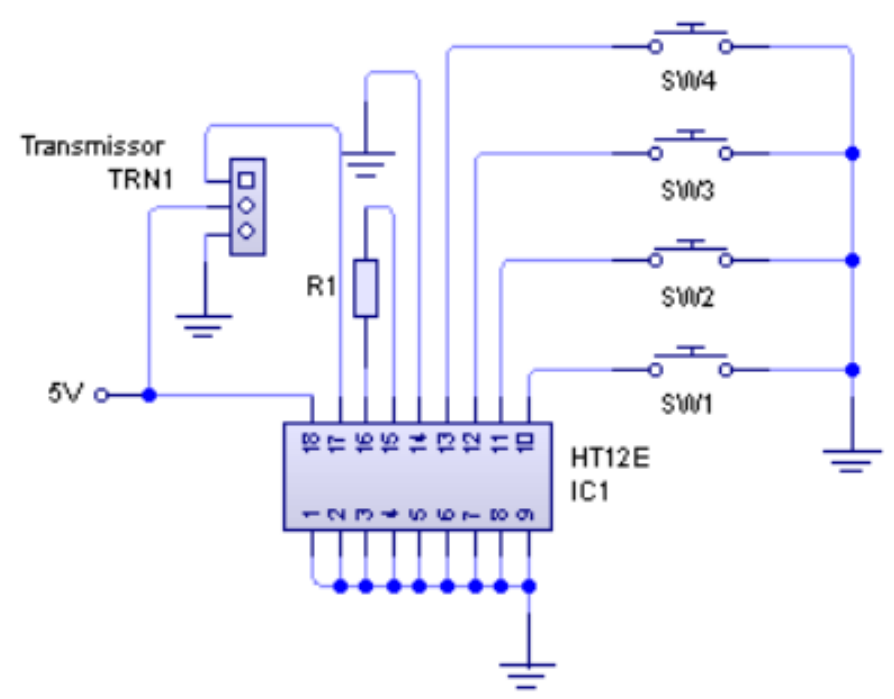

Fonte: Os autores

O protótipo do circuito de controle pode ser visto na Figura 11.

Figura 11 - Protótipo do circuito de controle

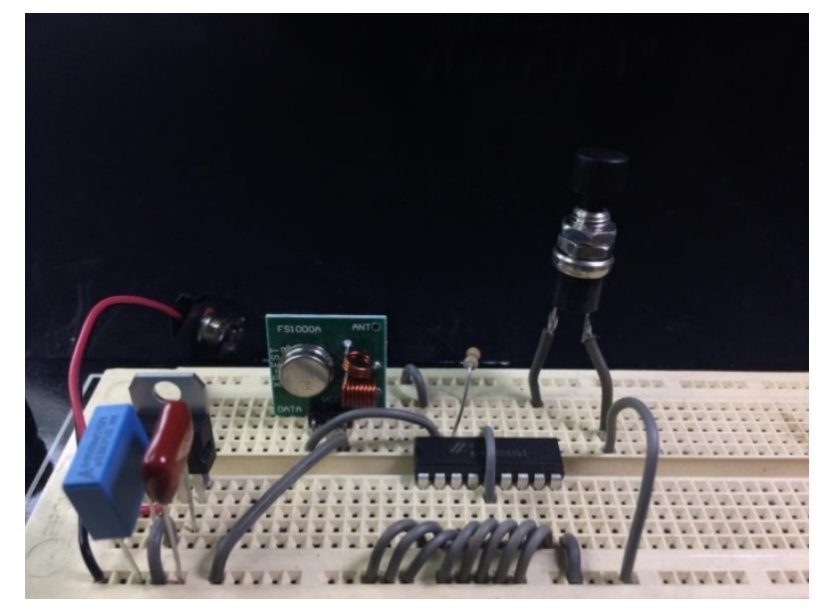

Fonte: Os autores

2.4. Detalhes do funcionamento dos atuadores

O circuito eletrônico dos atuadores será alimentado da mesma forma que o sistema de controle, conforme visto anteriormente em 2.3. Cada atuador terá a sua alimentação individual (9V convertidos para $5 \mathrm{~V}$ ) ao invés de utilizar a própria energia da instalação elétrica para alimentá-lo. A alimentação do circuito desta forma foi proposta para que se evitasse a queima de qualquer dos seus componentes devido a possíveis picos de energia, o que traria maiores complicações no que diz respeito ao reparo. O protótipo da fonte do sistema dos atuadores pode ser visto na Figura 12. 
Figura 12 - Tensão regulada da fonte do sistema dos atuadores

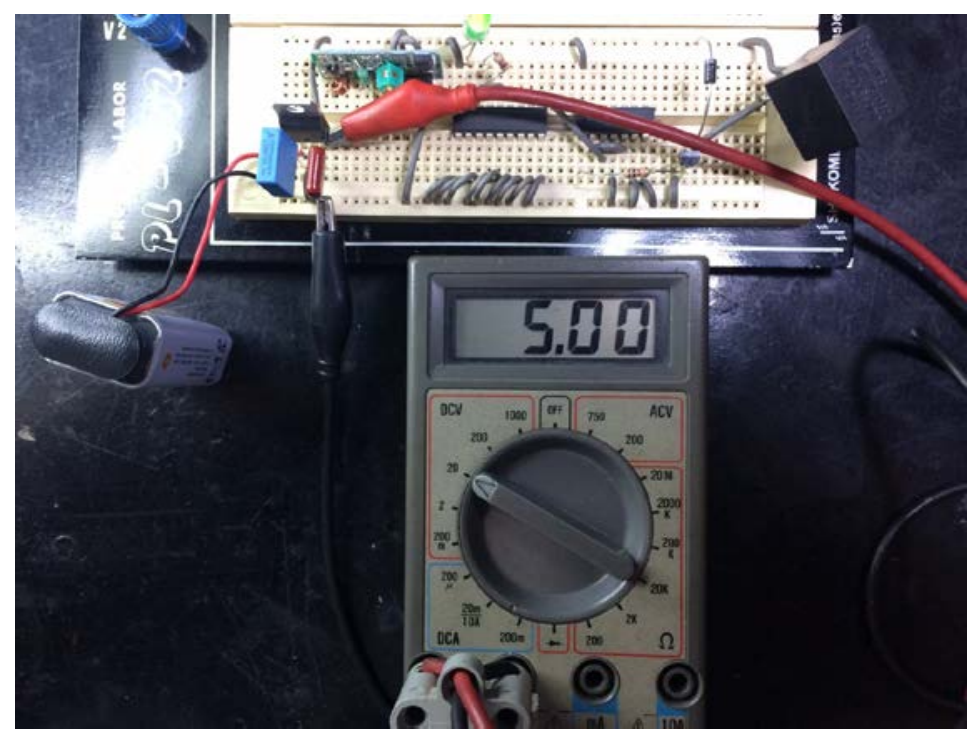

Fonte: Os autores

O circuito dos atuadores utiliza um módulo receptor $\mathrm{RF}$ de $433 \mathrm{MHz}$ para receber o sinal vindo do controle. Este módulo possui dois pinos que levarão a informação até o circuito integrado HT12D para ser decodificado. Os pinos Vcc e GND se referem à alimentação do receptor. A tensão de operação do receptor é de $5 \mathrm{~V}$, que deve ser mantida inalterada para que não comprometa os componentes do circuito.

Após a recepção correta do sinal, este deve passar para o pino 13 do circuito integrado HT12D, que fará a interpretação do sinal recebido e acionará uma das saídas localizadas nos pinos 10 ao 13 de acordo com a informação recebida, desde que a codificação do $\mathrm{Cl}$ esteja idêntica à codificação do HT12E, localizada nos pinos 1 ao 8. Este passo é importante para que o sinal seja interpretado apenas pelo componente a que se destina. Da mesma forma como no HT12E, o HT12D possui um resistor que controla a frequência de oscilação. Este resistor é determinado utilizando um critério que consta no seu datasheet e diz que a frequência de oscilação do decodificador deve ser 50 vezes maior que a do codificador. Sendo assim, a frequência será de $150 \mathrm{kHz}$. Utilizando o gráfico da Figura 13 é possível determinar o valor do resistor de oscilação utilizando o critério descrito anteriormente e a tensão de alimentação do circuito, que deverá fornecer um valor de resistor de $51 \mathrm{k} \Omega$. 
Figura 13 - Gráfico de frequência vs. tensão de alimentação do HT12D

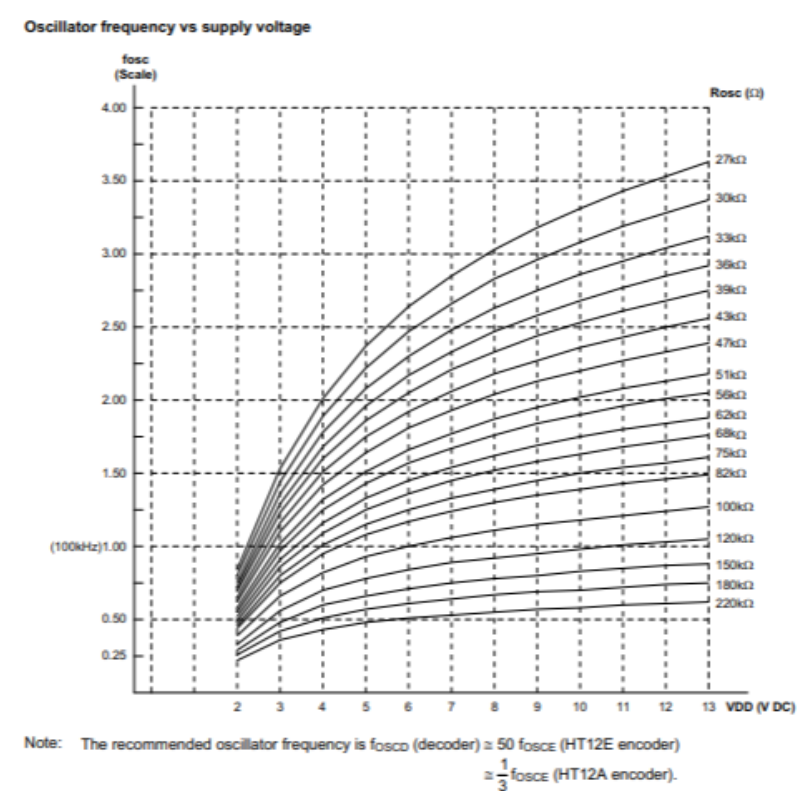

Fonte: Adaptado de http://www.farnell.com/datasheets/57850.pdf, acessado em 09/07/2019

Um LED ligado ao pino 17 será responsável por indicar o recebimento do sinal. Isso irá provar que a transmissão do sinal a partir do controle será para todos os atuadores, mas apenas o que contiver a codificação adequada, conseguirá interpretar e executar o comando. A Figura 14 mostra o circuito receptor.

Figura 14 - Circuito receptor

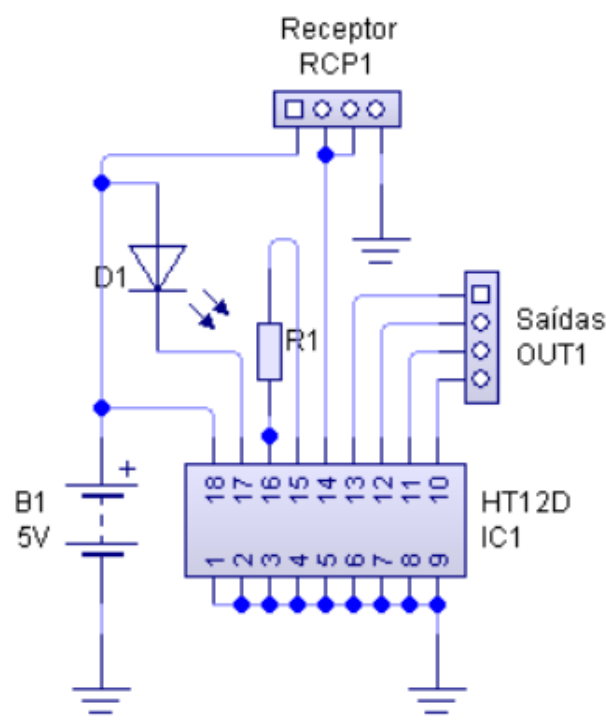

Fonte: Os autores

Neste ponto é importante ressaltar que dependendo da carga que for aplicada na saída do circuito atuador, ou seja, aquele equipamento que será automatizado, talvez se faça necessária uma alteração do relé que fará o chaveamento. Isso acontece porque a corrente que atravessará os terminais do relé pode em dado momento ser maior do que aquela que o componente suporta, 
podendo provocar o aquecimento extremo e/ou queima do componente. Mas para os objetos propostos neste projeto, os relés de 125/250Vac com capacidade de suportar até $10 \mathrm{~A}$, de acordo com a especificação do fabricante, serão adequados ao fim que se designam.

Assim que o sinal for recebido uma das saídas será acionada. Aqui vale lembrar que os botões do controle são normalmente abertos e voltam a esta condição quando deixam de ser pressionados. Logo, para que o equipamento continue ligado mesmo após o botão de controle ter sido solto, será utilizado um flip-flop tipo $D$, para que quando o sinal seja recebido ele mantenha o nível alto até que outro pulso vindo do mesmo botão faça com que o flip-flop volte à condição anterior de nível baixo. A saída do flip-flop será ligada a um transistor modelo NPN que funcionará como chave eletrônica. Quando a tensão Vbe for $0,7 \mathrm{~V}$ o transistor começará a conduzir no sentido coletoremissor, isso fará com que a tensão de alimentação do circuito passe pela bobina do relé e acione o contato, permitindo desta maneira o fluxo de corrente através do equipamento automatizado. Vale lembrar que a bobina do relé não deve ser ligada diretamente na saída do flip-flop, tal ligação poderia causar a queima do componente por variações de corrente na bobina do relé. Por isso se faz necessária a utilização do transistor que além de chave eletrônica atuará como um fator de proteção para o restante do circuito. A figura Figura 15 mostra o circuito do atuador.

Figura 15 - Circuito do atuador

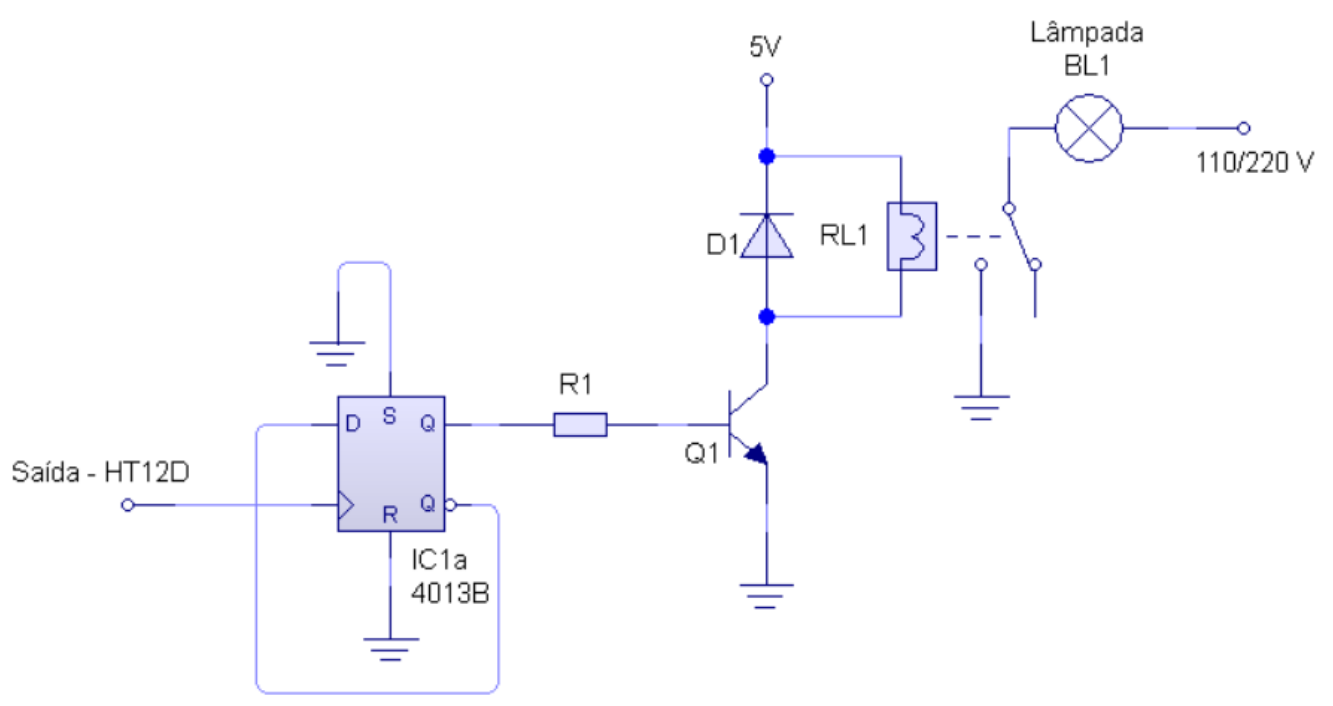

Fonte: Os autores

\subsection{Teste Funcional do Protótipo}

Para verificar o funcionamento do projeto como um todo, foi realizado o teste utilizando um multímetro na função de continuidade para comprovar que o acionamento do circuito transmissor 
era realmente capaz de acionar o relé no circuito atuador. No primeiro momento o multímetro apresenta resistência infinita, mostrando que o contato está aberto (como visto na Figura 16) e no segundo momento apresenta resistência baixíssima, mostrando que o contato foi acionado (como visto na Figura 17).

Após os testes foi verificado que o circuito funciona corretamente e a carga poderá ser acionada via rádio frequência. Experimentalmente, verificou-se que os comandos enviados por cada botão do controle apenas acionam a sua saída correspondente no receptor. Não houve nenhum tipo de interferência do sinal devido à codificação do receptor e o flip-flop manteve o circuito em funcionamento até que um novo pulso fosse enviado. Desta forma, não é necessário exigir do transmissor um sinal constante, o que poderia acarretar uma perda de carga da bateria mais rapidamente.

Figura 16 - Teste de funcionamento com o relé desativado

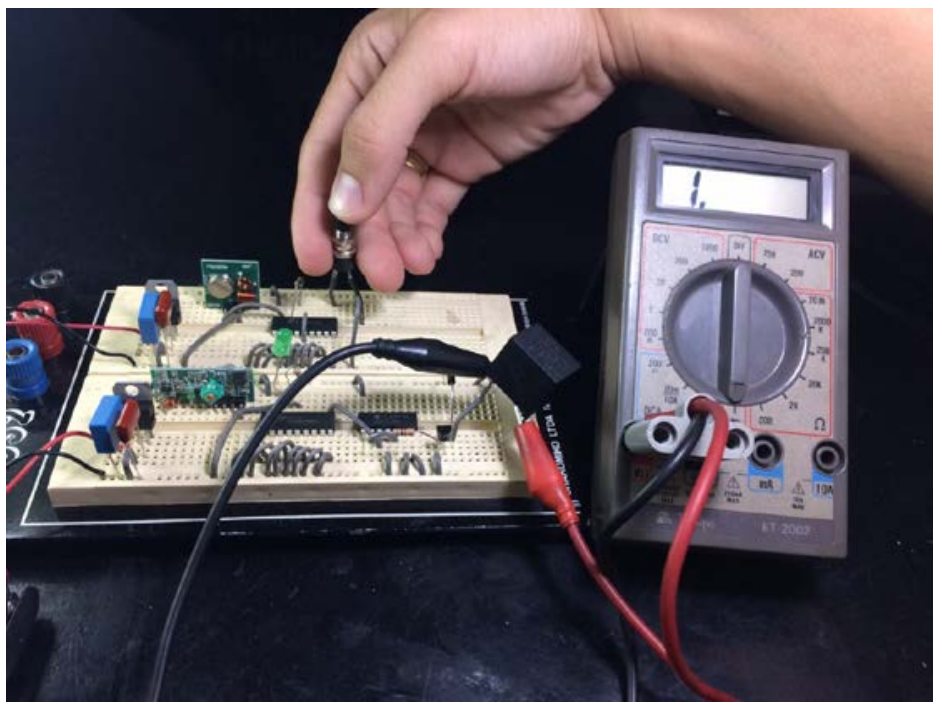

Fonte: Os autores

Figura 17 - Teste de funcionamento com o relé ativado

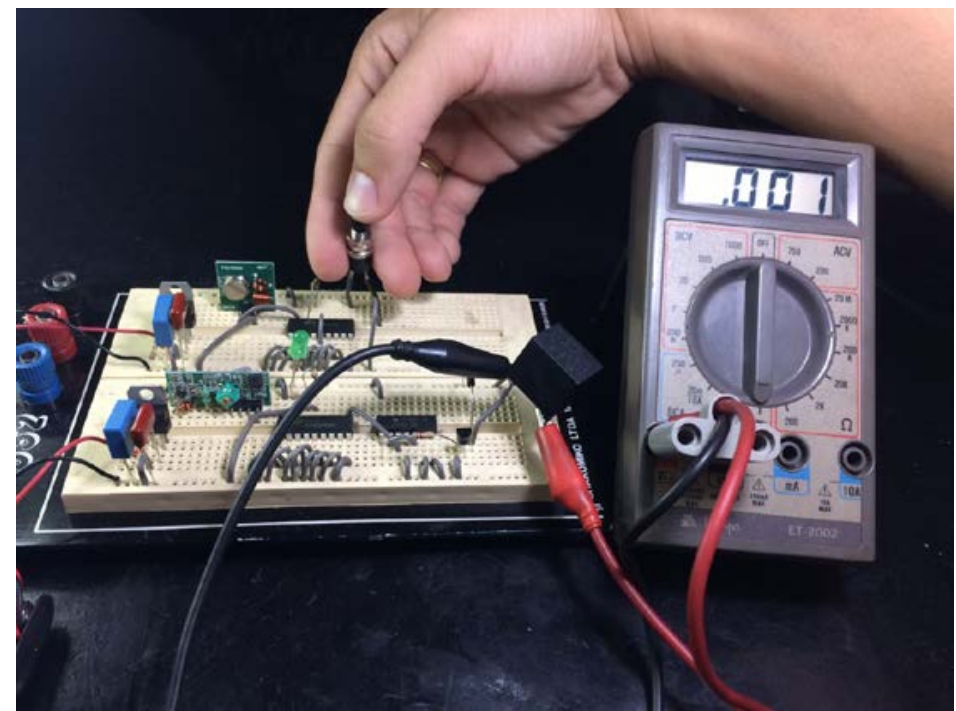

Fonte: Os autores 


\subsection{Equipamentos a serem automatizados}

De acordo com a proposta do projeto, cada equipamento que será automatizado precisará estar ligado a um dos atuadores que por sua vez deverá estar conectado na rede elétrica. Sendo assim, é possível citar exemplos como lâmpadas, abajures, trancas elétricas de portas, trancas elétricas de portões, acionamento de portões automáticos, motores (estes podem ser conectados em janelas ou cortinas para controlar a sua abertura e fechamento), ventiladores, aparelhos de arcondicionado, televisões e aparelhos de som. Estes três últimos dependem também do acionamento do controle individual de cada um, fornecido pelo fabricante para exercerem as suas funções. Por isso esse trabalho se dedica a equipamentos que possam funcionar de forma plena utilizando apenas o circuito de rádio frequência em questão, uma vez que os três aparelhos citados anteriormente já possuem seus controles individuais para serem acionados.

\subsection{Instalação dos atuadores}

A instalação dos atuadores deve ser feita levando em consideração que a sua utilização não deve excluir o uso dos interruptores tradicionais, pois nos casos em que o circuito pare de funcionar o equipamento não deve deixar de poder ser acionado e este acionamento deverá ser feito através do próprio interruptor. A sua instalação junto aos equipamentos a serem automatizados será feita de forma a chavear o condutor fase de tais equipamentos. Isso fará com que o aparelho seja ligado através do circuito de rádio frequência. A chave manual que fará a comutação entre o sistema e o interruptor tradicional da instalação só deverá ser acionada no caso de defeito do circuito. A chave ficará acoplada junto à caixa do atuador de forma que a sua utilização seja bem acessível.

\subsection{Aplicação Prática do Protótipo em uma Residência}

O protótipo foi adicionado numa instalação elétrica de forma a realizar o acionamento de uma lâmpada simples. O projeto se mostrou eficiente, apresentando o resultado esperado. Utilizando a chave by-pass do atuador, o interruptor tradicional da instalação pôde ser utilizado normalmente, isso confirma que caso o atuador apresente defeito será possível continuar utilizando qualquer objeto no qual o atuador for ligado mesmo sem ter que retirá-lo da instalação da casa. A Figura 18 representa o teste realizado de forma prática em uma residência. $\mathrm{O}$ acionamento foi realizado dentro do mesmo cômodo e em outros cômodos da residência, a uma distância 
aproximada de $10 \mathrm{~m}$ onde neste meio havia paredes que dividiam os cômodos e mesmo assim não houve interrupção do sinal ou qualquer tipo de interferência momentânea.

Figura 18 - Aplicação prática do protótipo
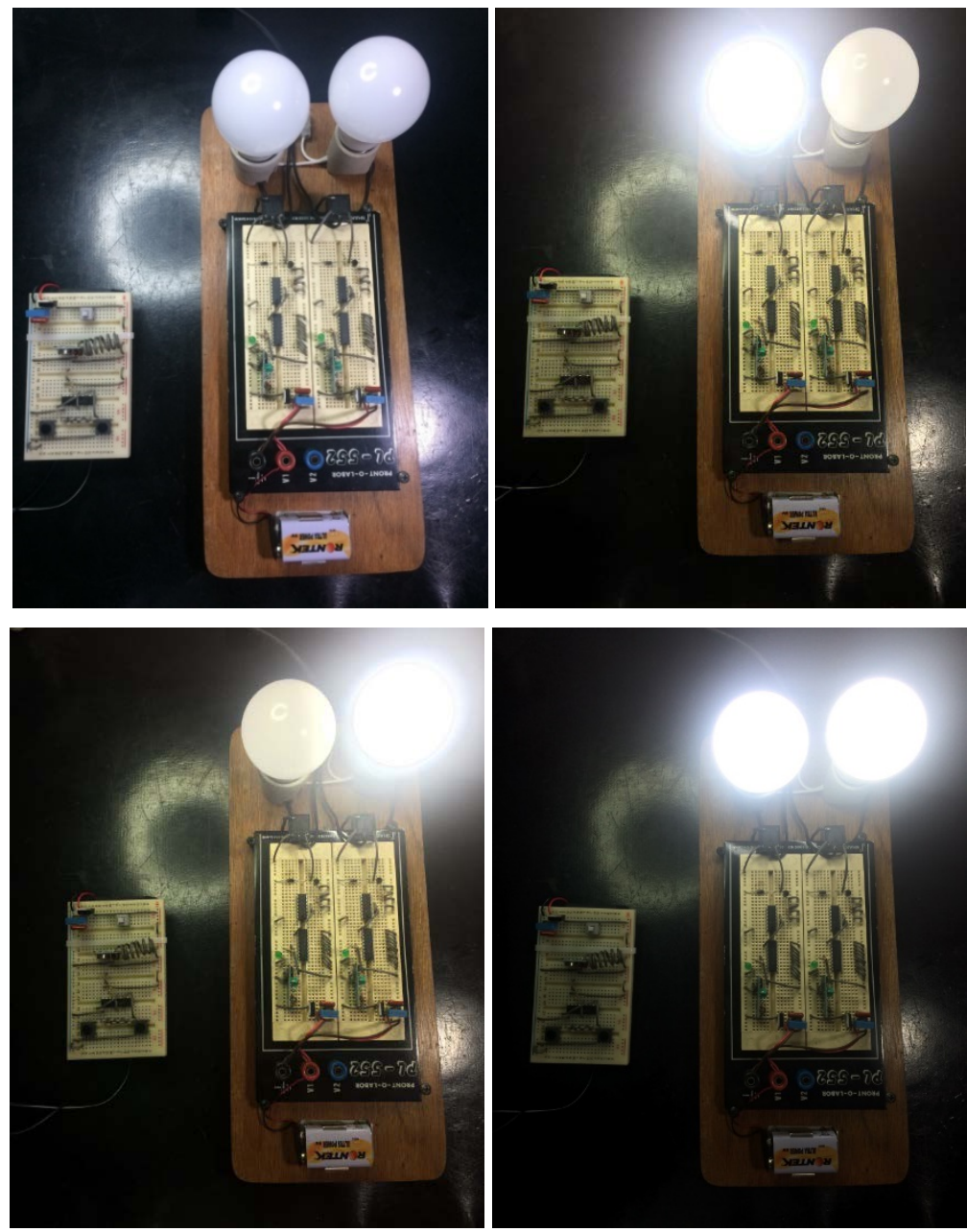

Fonte: Os autores

\subsection{Cálculos de custos do protótipo}

Após serem realizados todos os passos para a construção do protótipo, é possível determinar o seu custo com a finalidade de se validar o objetivo do trabalho. O cálculo dos custos levará em conta todo o material utilizado para realizar a construção do projeto e a implantação de uma unidade em uma residência, o controle construído terá dois botões para acionamento e desligamento dos comandos. Nas tabelas seguintes também serão considerados os valores de placas cobreadas de circuitos eletrônicos para realizar a montagem. 


\subsubsection{Componentes do controle}

A Tabela 4 se refere aos componentes que constituem o controle do sistema de automação residencial.

Tabela 4 - Componentes do Controle

\begin{tabular}{|c|c|c|c|}
\hline Componente & Quantidade & Valor unitário (R\$) & Valor final (R\$) \\
\hline Capacitor $0.1 \mu \mathrm{F}$ & 01 & 1,00 & 1,00 \\
\hline Capacitor $0.33 \mu \mathrm{F}$ & 01 & 1,50 & 1,50 \\
\hline LM7805 & 01 & 2,00 & 2,00 \\
\hline Transmissor RF 433MHz & 01 & 6,00 & 6,00 \\
\hline CI HT12E & 01 & 10,00 & 10,00 \\
\hline Resistor $1 \mathrm{M} \Omega$ & 01 & 0,20 & 0,20 \\
\hline Push button NA & 02 & 4,50 & 9,00 \\
\hline Bateria 9V & 01 & 8,50 & 8,50 \\
\hline Placa de circuito impresso & 01 & 13,00 & 13,00 \\
\hline TOTAL & & & $\mathrm{R} \$ 51,20$ \\
\hline
\end{tabular}

Fonte: Os autores

2.9.2. Componentes dos atuadores

A Tabela 5 se refere aos componentes que constituem os atuadores do sistema de automação residencial.

Tabela 5 - Componentes dos Atuadores

\begin{tabular}{|c|c|c|c|}
\hline Componente & Quantidade & Valor unitário (R\$) & Valor final (R\$) \\
\hline Capacitor $0.1 \mu \mathrm{F}$ & 01 & 1,00 & 1,00 \\
\hline Capacitor $0.33 \mu \mathrm{F}$ & 01 & 1,50 & 1,50 \\
\hline LM7805 & 01 & 2,00 & 2,00 \\
\hline Receptor RF 433MHz & 01 & 6,00 & 6,00 \\
\hline CI HT12D & 01 & 10,00 & 10,00 \\
\hline Cl CD4013 & 01 & 2,50 & 2,50 \\
\hline Resistor $51 \mathrm{k} \Omega$ & 01 & 0,20 & 0,20 \\
\hline Resistor $1 \mathrm{k} \Omega$ & 01 & 0,20 & 0,20 \\
\hline Led verde & 01 & 0,30 & 0,30 \\
\hline Transistor BC548 & 01 & 0,50 & 0,50 \\
\hline Diodo 1N4007 & 01 & 0,20 & 0,20 \\
\hline Relé 5V & 01 & 5,00 & 5,00 \\
\hline Bateria 9V & 01 & 8,50 & 8,50 \\
\hline Placa de circuito impresso & 01 & 13,00 & 13,00 \\
\hline TOTAL & & & $\mathrm{R} \$ 50,90$ \\
\hline
\end{tabular}

Fonte: Os autores

\subsubsection{Custo total do projeto}

A Tabela 6 se refere ao custo envolvido no projeto de automação residencial. 
Tabela 6 - Custo total do projeto

\begin{tabular}{|c|c|}
\hline Custo do controle & $\mathrm{R} \$ 51,20$ \\
\hline Custo do atuador & $\mathrm{R} \$ 50,90$ \\
\hline TOTAL & $\mathrm{R} \$ 102,10$ \\
\hline \multicolumn{2}{|c|}{ Fonte: Os autores } \\
\hline
\end{tabular}

\section{CONSIDERAÇÕES FINAIS}

O desenvolvimento do projeto possibilitou a redução do custo geral de um sistema de automação residencial, baseando-se para isso em transmissão via rádio frequência. Esta redução poderá aumentar a quantidade de pessoas que viriam a adquirir tal produto que, em outras circunstâncias, possuiria um valor muito mais elevado (neste caso, $\mathrm{R} \$ 195,18$ ). Ao fazer o teste do projeto verificou-se que não apenas o custo foi reduzido, mas também a forma como o projeto é implementado. Vale ressaltar que os atuadores, por serem dependentes de uma alimentação por bateria, podem descarregar com o tempo e ser necessário que cada uma delas seja substituída conforme a necessidade.

Sendo assim, o objetivo principal do projeto foi alcançado. Conforme o resultado do desenvolvimento do projeto, o custo envolvendo todo o sistema $(R \$ 102,10)$ se mostrou muito menor do que aqueles com os quais este foi comparado (Tabela 7), chegando a custar aproximadamente $48 \%$ mais barato que o sistema de automação mais barato (dispositivos cabeados) e aproximadamente $79 \%$ mais barato que o sistema de automação mais caro.

Tabela 7 - Comparação de custos em relação a Automação Residencial RF (R\$102,10)

\begin{tabular}{|l|r|r|r|}
\hline \multicolumn{1}{|c|}{ Produto } & \multicolumn{1}{|c|}{ Custo (R\$) } & Diferença (R\$) & Custo relativo (\%) \\
\hline Dispositivos cabeados & 195,18 & 93,08 & 47,69 \\
\hline Dispositivos sem fio & 494,16 & 392,06 & 79,34 \\
\hline Arduino + Ethernet Shield & 327,00 & 224,90 & 68,78 \\
\hline
\end{tabular}

Visto que o custo foi reduzido, a sua instalação poderá agora ser alcançada por uma maior parcela da população que poderia não ter acesso sob outras condições. Esse assunto se torna tão importante porque não permite apenas aumentar o conforto dentro da casa, mas também fornece acessibilidade para pessoas que possuem determinadas deficiências físicas que a impedem de realizar algumas funções. Nesse sentido, a utilização desses recursos digitais se torna extremamente útil e agradável ao usuário que pode agora realizar tarefas do dia a dia com mais praticidade e comodismo. 


\section{REFERÊNCIAS}

ABREU, E. R. D.; VALIM, P. R. O. Domótica: Controle de Automação Residencial Utilizando Celulares com Bluetooth. SEGeT. Resende, p. 14. 2011.

AGOSTINETTO, J. S. Sistematização do processo de desenvolvimento de produtos, melhoria contínua e desempenho: o caso de uma empresa de autopeças. Dissertação de Mestrado. São Carlos: Universidade de São Paulo, 2006. 121 p.

BACK, M. Arduino Mais, 2014. Disponivel em: <http://arduinomais.blogspot.com/2014/05/resistorpull-up-e-pull-down.html>. Acesso em: 26 fev. 2019.

DUARTE, F. Bluelux, 2018. Disponivel em: <https://www.bluelux.com.br/5-vantagens-daautomacao-residencial-sem-fio/>. Acesso em: 29 Outubro 2018.

FRACCHETTA, A., $2016 . \quad$ Disponivel em: <http://www.forumdaconstrucao.com.br/conteudo.php?a=11\&Cod=1832>. Acesso em: 23 set. 2018.

HOME THEATER E CASA DIGITAL. Home Theater e Casa Digital, 2017. Disponivel em: $<$ http://revistahometheater.uol.com.br/portal/2017/12/21/automacao-funciona-via-wi-fi-semcentral-de-controle/>. Acesso em: 20 nov. 2018.

IBYTES. iBytes, 2016. Disponivel em: <https://www.ibytes.com.br/circuitos-integrados-ht12d-emodulos-de-rf-433-mhz/>. Acesso em: 25 nov. 2018.

KURTZ, J. TechTudo, 2016. Disponivel em: <https://www.techtudo.com.br/dicas-etutoriais/noticia/2016/03/o-que-e-software-de-codigo-aberto.html>. Acesso em: 25 nov. 2018.

LAMBRECHT, A. Ebah, $2006 . \quad$ Disponivel em: <https://www.ebah.com.br/content/ABAAAABUgAA/x10>. Acesso em: 20 nov. 2018.

LENZ, A. L., 2012. Disponivel em: <http://info-domotica.blogspot.com/2012/12/a-pre-historia-dadomotica.html>. Acesso em: 30 set. 2018.

LIMA, E. M. S.; NOBRE, A. Y. M.; ALENCAR, R. A. E. D. AUTOMAÇÃO RESIDENCIAL DE BAIXO CUSTO COM ARDUINO MEGA E ETHERNET SHIELD. Centro Universitário Estácio do Ceará. Ceará, p. 17. 2015.

MANS, M. Estadão, 2015. Disponivel em: <https://link.estadao.com.br/noticias/gadget,casainteligente-entra-no-radar-do-brasileiro-e-vira-alvo-de-varias-industrias,10000028829>. Acesso em: 29 Outubro 2018.

MATTOS, M. TMC Telecomunicações, 2018. Disponivel em: <http://www.tmctelecomunicacoes.com.br/site/blog/automacao-residencial-cresce-no-mundo/>. Acesso em: 25 nov. 2018. 
MOTA, A. Vida de Silício, 2017. Disponivel em: <https://portal.vidadesilicio.com.br/o-que-earduino-e-como-funciona/>. Acesso em: 25 nov. 2018.

MURATORI, J. R. AURESIDE, Dezembro 2017. Disponivel em: <http://aureside.blogspot.com/2018/01/utilizando-tecnologia-para-atender-os.html>. Acesso em: 25 nov. 2018.

MURATORI, J. R., 2017. Disponivel em: <http://aureside.blogspot.com/2017/11/vinte-anos-deautomacao-residencial-no.html>. Acesso em: 30 set. 2018.

MURTA, G. Eletrogate, 2019. Disponivel em: <http://blog.eletrogate.com/guia-basico-dosmodulos-tx-rx-rf-433mhz/>. Acesso em: 26 fev. 2019.

OLIVEIRA, E. Master Walker Electronic Shop, 2018. Disponivel em: <http://blogmasterwalkershop.com.br/arduino/arduino-utilizando-o-ethernet-shield-w5100-viaweb-server/>. Acesso em: 25 nov. 2018.

SANTOS, D. D. M. S. D. SISTEMA DE AUTOMAÇÃO RESIDENCIAL ESCALÁVEL E SEM FIO UTILIZANDO TECNOLOGIAS DE BAIXO CUSTO, Vale do Itajaí, 3 Setembro 2014. 76-86.

SILVA, T. D. $\quad$ i12eletrica, $2012 . \quad$ Disponivel em: <http://i12eletrica.blogspot.com/2012/10/transmissao-de-dados-em-rede-serial.html>. Acesso em: 26 fev. 2019.

SOUZA, F. Embarcados, 2014. Disponivel em: <https://www.embarcados.com.br/arduino-mega2560/>. Acesso em: 25 nov. 2018.

TESTE. [S.I.]: [s.n.], 12.

TEZA, V. R. ALGUNS ASPECTOS SOBRE A AUTOMAÇÃO RESIDENCIAL - DOMÓTICA. UNIVERSIDADE FEDERAL DE SANTA CATARINA. Florianópolis, p. 108. 2002.

VIPHOME. VipHome, 2018. Disponivel em: <http://www.viphome.com.br/historia-da-automacaoresidencial/>. Acesso em: 25 nov. 2018.

WINK. WINK, 2018. Disponivel em: <https://www.wink.com>. Acesso em: 23 nov. 2018.

WORTMEYER, C.; FREITAS, F.; CARDOSO, L. Automação Residencial: Busca de Tecnologias visando o Conforto, a Economia, a Praticidade e a Segurança do Usuário. Associação Educacional Dom Bosco - AEDB. Resende, p. 4. 2005.

X10 HOME AUTOMATION. X10, 2018. Disponivel em: <https://www.x10.com/x10-homeautomation.html>. Acesso em: 23 nov. 2018. 